\title{
A New Group of Heterocyclic Nitrogenous Disinfection Byproducts (DBPs) in Drinking Water: Role of Extraction pH in Unknown DBP Exploration
}

\author{
Haiyang Tang, ${ }^{\dagger}$ Hongli Zhong, ${ }^{\dagger}$ Yang Pan, ${ }^{*}{ }^{\dagger}$ Qing Zhou,${ }^{\dagger}$ Zongli Huo, ${ }^{\ddagger}$ Wenhai Chu,${ }^{\S}$ Bin $\mathrm{Xu}^{\S}$
}

'State Key Laboratory of Pollution Control and Resource Reuse, School of the Environment, Nanjing University, Nanjing 210023, Jiangsu, China

$\$$ Jiangsu Provincial Center for Disease Control and Prevention, No.172 Jiangsu Road, Nanjing 210009, Jiangsu, China

${ }^{\$}$ State Key Laboratory of Pollution Control and Resource Reuse, College of Environmental Science and Engineering, Tongji University, Shanghai, 200092, China

\section{Contents of Supporting Information}

Derivation process of Equations (3) to (5)

Table S1. The pKa values of 59 possible halogenated pyridinols.

Table S2. MS parameters before and after optimization for the detection and quantitation of the eight new DBPs.

Figure S1. The distribution pattern of three dissociated species of 3-pyridinol with pH.

Figure S2. (a-c) UPLC/ESI-tqMS MRM $(128 \rightarrow 35,130 \rightarrow 37)$ chromatograms of a 5-chloro-3-pyridinol standard, the simulated drinking water sample, and the water sample spiked with 5-chloro-3-pyridinol, respectively; (dg) UPLC/ESI-tqMS product ion scan spectra of $m / z, 128 / 130$ of the water sample and the 5-chloro-3-pyridinol standard, respectively. The $y$-axes of charts (b) and (c) are on the same scale.

Figure S3. (a-c) UPLC/ESI-tqMS MRM $(172 \rightarrow 79,174 \rightarrow 81)$ chromatograms of a 2-bromo-3-pyridinol standard, the simulated drinking water sample, and the water sample spiked with 2-bromo-3-pyridinol, respectively; (d-g) UPLC/ESI-tqMS product ion scan spectra of $m / z, 172 / 174$ of the water sample and the 2bromo-3-pyridinol standard, respectively. The $y$-axes of charts (b) and (c) are on the same scale.

Figure S4. (a-c) UPLC/ESI-tqMS MRM $(162 \rightarrow 35,164 \rightarrow 35 / 37,166 \rightarrow 37)$ chromatograms of a 2,6-dichloro-4pyridinol standard, the simulated drinking water sample, and the water sample spiked with 2,6-dichloro-4pyridinol, respectively; (d-i) UPLC/ESI-tqMS product ion scan spectra of $m / z$ 162/164/166 of the water sample and the 2,6-dichloro-4-pyridinol standard, respectively. The y-axes of charts (b) and (c) are on the same scale.

Figure S5. (a-c) UPLC/ESI-tqMS MRM $(250 \rightarrow 79,252 \rightarrow 79 / 81,254 \rightarrow 81)$ chromatograms of a 2,6-dibromo-3pyridinol standard, the simulated drinking water sample, and the water sample spiked with 2,6-dibromo-3pyridinol, respectively; (d-i) UPLC/ESI-tqMS product ion scan spectra of $m / z 250 / 252 / 254$ of the water sample and the 2,6-dibromo-3-pyridinol standard, respectively. The y-axes of charts (b) and (c) are on the same scale.

Figure S6. (a-c) UPLC/ESI-tqMS MRM $(206 \rightarrow 79,208 \rightarrow 79 / 81,210 \rightarrow 81)$ chromatograms of a 3-bromo-2chloro-5-pyridinol standard, the simulated drinking water sample, and the water sample spiked with 3-bromo- 
2-chloro-5-pyridinol, respectively; (d-i) UPLC/ESI-tqMS product ion scan spectra of $m / z, 206 / 208 / 210$ of the water sample and the 3-bromo-2-chloro-5-pyridinol standard, respectively. The $y$-axes of charts (b) and (c) are on the same scale.

Figure S7. (a-c) UPLC/ESI-tqMS MRM $(206 \rightarrow 79,208 \rightarrow 79 / 81,210 \rightarrow 81)$ chromatograms of a 5-bromo-2chloro-3-pyridinol standard, the simulated drinking water sample, and the water sample spiked with 5-bromo2-chloro-3-pyridinol, respectively; (d-i) UPLC/ESI-tqMS product ion scan spectra of $m / z, 206 / 208 / 210$ of the water sample and the 5-bromo-2-chloro-3-pyridinol standard, respectively. The y-axes of charts (b) and (c) are on the same scale.

Figure S8. (a-c) UPLC/ESI-tqMS MRM $(328 \rightarrow 79,330 \rightarrow 79 / 81,332 \rightarrow 79 / 81,334 \rightarrow 81)$ chromatograms of a 2,4,6-tribromo-3-pyridinol standard, the simulated drinking water sample, and the water sample spiked with 2,4,6-tribromo-3-pyridinol, respectively; (d-k) UPLC/ESI-tqMS product ion scan spectra of $\mathrm{m} / \mathrm{z}$ $328 / 330 / 332 / 334$ of the water sample and the 2,4,6-tribromo-3-pyridinol standard, respectively. The $y$-axes of charts (b) and (c) are on the same scale.

Figure S9. (a-h) The distribution patterns of the dissociated species of 5-chloro-3-pyridinol, 2-bromo-3pyridinol, 2,6-dichloro-4-pyridinol, 2,6-dibromo-3-pyridinol, 3-bromo-2-chloro-5-pyridinol, 5-bromo-2-chloro3-pyridinol, 3,5,6-trichloro-2-pyridinol, and 2,4,6-tribromo-3-pyridinol with $\mathrm{pH}$, respectively.

Figure S10. A comparison of peak areas in MRM chromatograms of (a) 5-chloro-3-pyridinol and (b) 2-bromo3-pyridinol at extraction $\mathrm{pH}$ of 0.5 and 3.0.

Figure S11. Morphological abnormalities of zebrafish embryos observed in the 2,4,6-tribromo-3-pyridinol exposure at 72 hpf. SYSE: shortened yolk sac extension; BT: bent tail; CS: curved spine; PE: pericardial edema; YSE: yolk sac edema; DD: developmental delay; SAV: separation of the atrium-ventricle. 


\section{Derivation process of Equations (3) to (5)}

For Equations (1) and (2),

$$
\begin{aligned}
& {[\mathrm{M}+\mathrm{H}]^{+} \rightleftharpoons[\mathrm{M}]+\mathrm{H}^{+} \quad K_{\mathrm{a} 1} \quad \text { Equation (1) }} \\
& {[\mathrm{M}] \rightleftharpoons[\mathrm{M}-\mathrm{H}]^{-}+\mathrm{H}^{+} \quad K_{\mathrm{a} 2} \quad \text { Equation (2) }} \\
& K_{\mathrm{a} 1}=\frac{[\mathrm{M}]\left[\mathrm{H}^{+}\right]}{[\mathrm{M}+\mathrm{H}]^{+}} \\
& K_{\mathrm{a} 2}=\frac{[\mathrm{M}-\mathrm{H}]^{-}\left[\mathrm{H}^{+}\right]}{[\mathrm{M}]}
\end{aligned}
$$

Since $\mathrm{pH}=-\log \left[\mathrm{H}^{+}\right]$, so that $\left[\mathrm{H}^{+}\right]=10^{-\mathrm{pH}}$

Since $\mathrm{p} K_{\mathrm{a} 1}=-\log K_{\mathrm{a} 1}$, so that $K_{\mathrm{a} 1}=10^{-\mathrm{p} K_{\mathrm{a} 1}}$

Since $\mathrm{p} K_{\mathrm{a} 2}=-\log K_{\mathrm{a} 2}$, so that $K_{\mathrm{a} 2}=10^{-\mathrm{p} K_{\mathrm{a} 2}}$

Suppose the fractions of $[\mathrm{M}],[\mathrm{M}+\mathrm{H}]^{+}$, and $[\mathrm{M}-\mathrm{H}]^{-}$are $\alpha_{1}, \alpha_{2}$, and $\alpha_{3}$, respectively. Accordingly,

$$
\alpha_{1}=\frac{[\mathrm{M}]}{[\mathrm{M}]+[\mathrm{M}-\mathrm{H}]^{-}+[\mathrm{M}+\mathrm{H}]^{+}}=\frac{[\mathrm{M}]}{[\mathrm{M}]+\frac{K_{\mathrm{a} 2}[\mathrm{M}]}{[\mathrm{H}]^{+}}+\frac{[\mathrm{M}]\left[\mathrm{H}^{+}\right]}{K_{\mathrm{a} 1}}}=\frac{1}{1+\frac{K_{\mathrm{a} 2}}{[\mathrm{H}]^{+}}+\frac{\left[\mathrm{H}^{+}\right]}{K_{\mathrm{a} 1}}}=\frac{1}{1+\frac{10^{-} \mathrm{p} K_{\mathrm{a} 2}}{10^{-}-\mathrm{pH}}+\frac{10^{-} \mathrm{pH}}{10^{-} \mathrm{p} K_{\mathrm{a} 1}}}=
$$

$\frac{1}{1+10\left(\mathrm{pH}-\mathrm{p} K_{\mathrm{a} 2}\right)}+10^{\left(\mathrm{p} K_{\mathrm{a} 1}-\mathrm{pH}\right)} \quad$ Equation (3)

$\alpha_{2}=\frac{[\mathrm{M}+\mathrm{H}]^{+}}{[\mathrm{M}]+[\mathrm{M}-\mathrm{H}]^{-}+[\mathrm{M}+\mathrm{H}]^{+}}=\frac{[\mathrm{M}+\mathrm{H}]^{+}}{\frac{K_{\mathrm{a} 1}[\mathrm{M}+\mathrm{H}]^{+}}{\left[\mathrm{H}^{+}\right]}+\frac{K_{\mathrm{a} 2}[\mathrm{M}]}{[\mathrm{H}]^{+}}+[\mathrm{M}+\mathrm{H}]^{+}}=\frac{1}{\frac{K_{\mathrm{a} 1}}{\left[\mathrm{H}^{+}\right]}+\frac{K_{\mathrm{a} 2} K_{\mathrm{a} 1}}{\left[\mathrm{H}^{+}\right]^{2}}+1}=\frac{1}{\frac{10^{-}-\mathrm{p} K_{\mathrm{a} 1}}{10^{-} \mathrm{pH}}+\frac{10^{-}-\mathrm{p} K_{\mathrm{a} 1}-\mathrm{p} K_{\mathrm{a} 2}}{10^{-2} \mathrm{pH}}+1}=$ $\frac{1}{10^{\left(\mathrm{pH}-\mathrm{p} K_{\mathrm{a} 1}\right)}+10^{\left(2 \mathrm{pH}-\mathrm{p} K_{\mathrm{a} 1}-\mathrm{p} K_{\mathrm{a} 2}\right)}+1} \quad$ Equation (4)

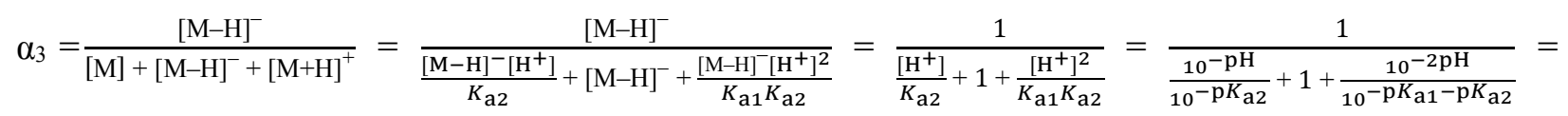
$\frac{1}{10^{\left(\mathrm{p} K_{\mathrm{a} 2}-\mathrm{pH}\right)}+1+10^{\left(\mathrm{p} K_{\mathrm{a} 1}+\mathrm{p} K_{\mathrm{a} 2}-2 \mathrm{pH}\right)}} \quad$ Equation (5) 
Table S1. The $\mathrm{p} K_{\mathrm{a}}$ values of 59 possible halogenated pyridinols.

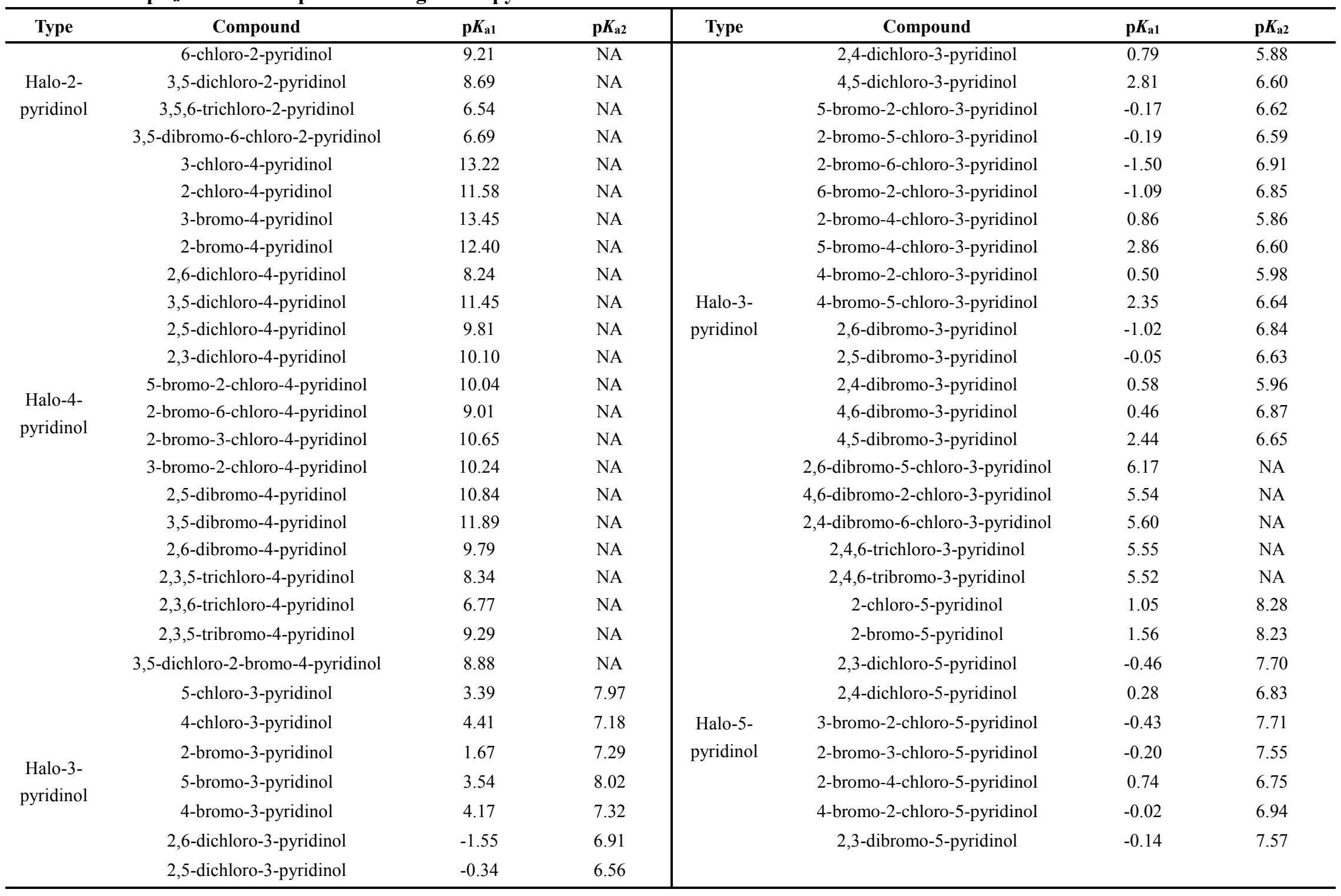


Table S2. MS parameters before and after optimization for the detection and quantitation of the eight new DBPs.

\begin{tabular}{|c|c|c|c|}
\hline MS parameter & & $\begin{array}{c}\text { Before } \\
\text { optimization }\end{array}$ & $\begin{array}{c}\text { After } \\
\text { optimization }\end{array}$ \\
\hline source temperature $\left({ }^{\circ} \mathrm{C}\right)$ & & 110 & 150 \\
\hline desolvation temperature $\left({ }^{\circ} \mathrm{C}\right)$ & & 400 & 600 \\
\hline capillary voltage $(\mathrm{kV})$ & & 2.8 & 2.5 \\
\hline cone gas flow rate $(\mathrm{L} / \mathrm{h})$ & & 50 & 50 \\
\hline desolvation gas flow rate $(\mathrm{L} / \mathrm{h})$ & & 800 & 700 \\
\hline \multirow{8}{*}{ cone voltage $(\mathrm{V})$} & 5-chloro-3-pyridinol & 30 & 26 \\
\hline & 2-bromo-3-pyridinol & 15 & 16 \\
\hline & 2,6-dichloro-4-pyridinol & 30 & 34 \\
\hline & 2,6-dibromo-3-pyridinol & 15 & 38 \\
\hline & 3-bromo-2-chloro-5-pyridinol & 15 & 30 \\
\hline & 5-bromo-2-chloro-3-pyridinol & 15 & 14 \\
\hline & 3,5,6-trichloro-2-pyridinol & 30 & 28 \\
\hline & 2,4,6-tribromo-3-pyridinol & 15 & 40 \\
\hline \multirow{8}{*}{ collision energy $(\mathrm{eV})$} & 5-chloro-3-pyridinol & 30 & 14 \\
\hline & 2-bromo-3-pyridinol & 20 & 12 \\
\hline & 2,6-dichloro-4-pyridinol & 30 & 18 \\
\hline & 2,6-dibromo-3-pyridinol & 20 & 20 \\
\hline & 3-bromo-2-chloro-5-pyridinol & 20 & 16 \\
\hline & 5-bromo-2-chloro-3-pyridinol & 20 & 18 \\
\hline & 3,5,6-trichloro-2-pyridinol & 30 & 12 \\
\hline & 2,4,6-tribromo-3-pyridinol & 20 & 28 \\
\hline \multirow{7}{*}{ dwell time (s) } & $\begin{array}{l}\text { 5-chloro-3-pyridinol } \\
\text { 2-bromo-3-pyridinol }\end{array}$ & \multirow{7}{*}{0.05} & \multirow[t]{2}{*}{0.165} \\
\hline & 2,6-dichloro-4-pyridinol & & \\
\hline & 2,6-dibromo-3-pyridinol & & 0082 \\
\hline & 3-bromo-2-chloro-5-pyridinol & & 0.082 \\
\hline & 5-bromo-2-chloro-3-pyridinol & & \multirow{3}{*}{0.054} \\
\hline & 3,5,6-trichloro-2-pyridinol & & \\
\hline & 2,4,6-tribromo-3-pyridinol & & \\
\hline
\end{tabular}




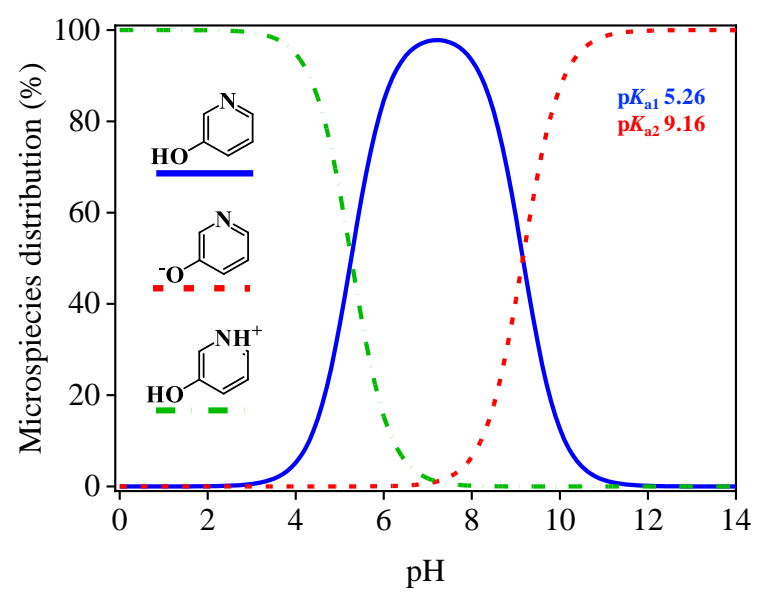

Figure S1. The distribution pattern of three dissociated species of 3-pyridinol with pH.

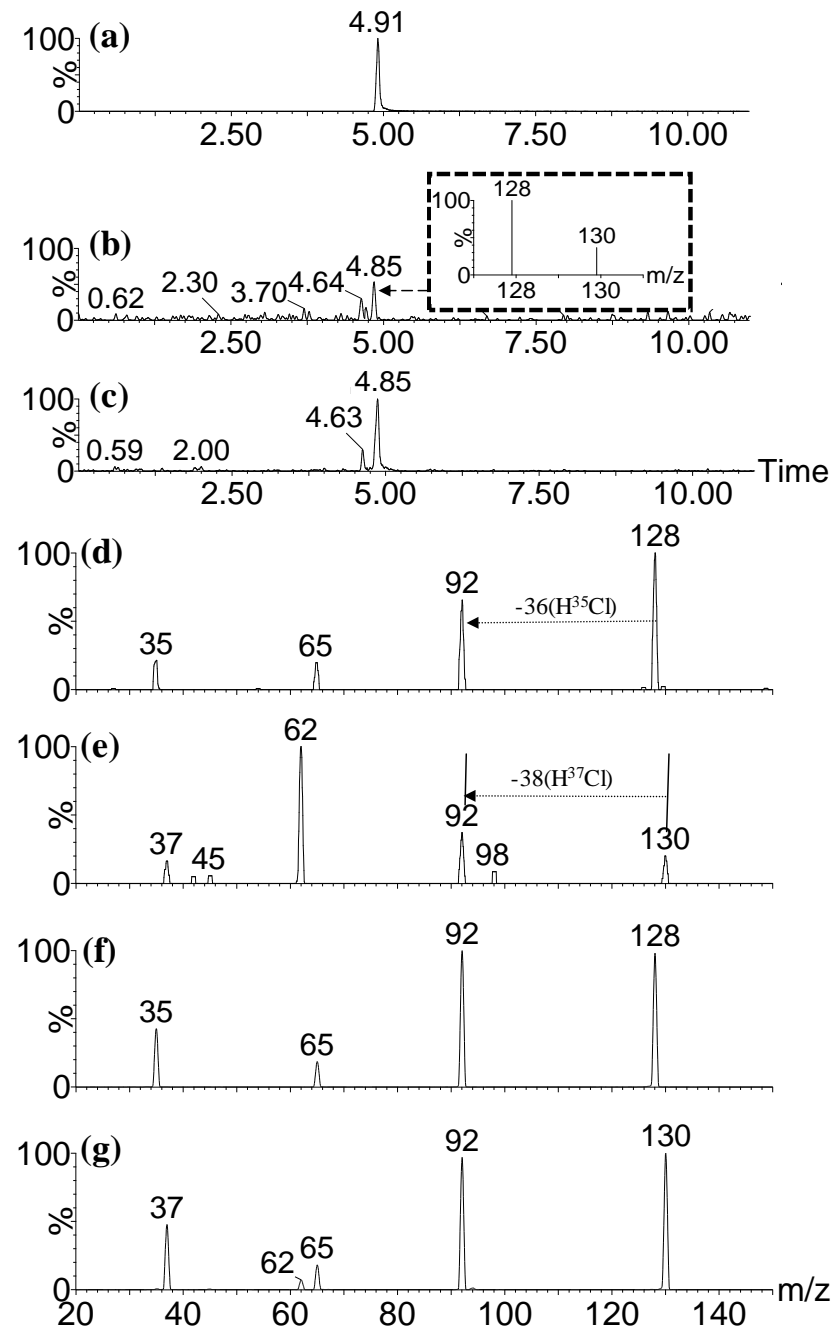

Figure S2. (a-c) UPLC/ESI-tqMS MRM $(128 \rightarrow 35,130 \rightarrow 37)$ chromatograms of a 5-chloro-3pyridinol standard, the simulated drinking water sample, and the water sample spiked with 5chloro-3-pyridinol, respectively; (d-g) UPLC/ESI-tqMS product ion scan spectra of $m / z$ 128/130 of the water sample and the 5-chloro-3-pyridinol standard, respectively. The y-axes of charts (b) and (c) are on the same scale. 

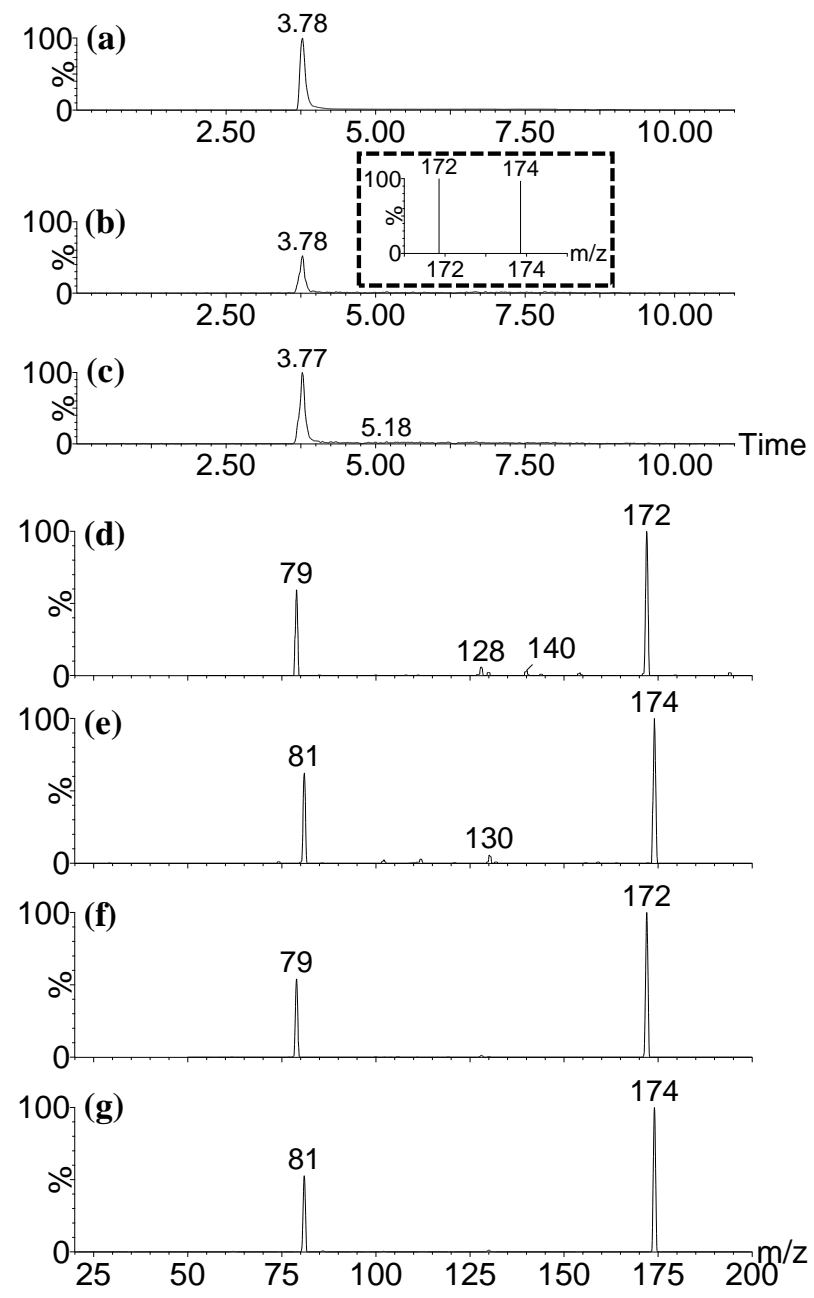

Figure S3. (a-c) UPLC/ESI-tqMS MRM $(172 \rightarrow 79,174 \rightarrow 81)$ chromatograms of a 2-bromo-3pyridinol standard, the simulated drinking water sample, and the water sample spiked with 2bromo-3-pyridinol, respectively; (d-g) UPLC/ESI-tqMS product ion scan spectra of $m / z, 172 / 174$ of the water sample and the 2-bromo-3-pyridinol standard, respectively. The y-axes of charts (b) and (c) are on the same scale. 


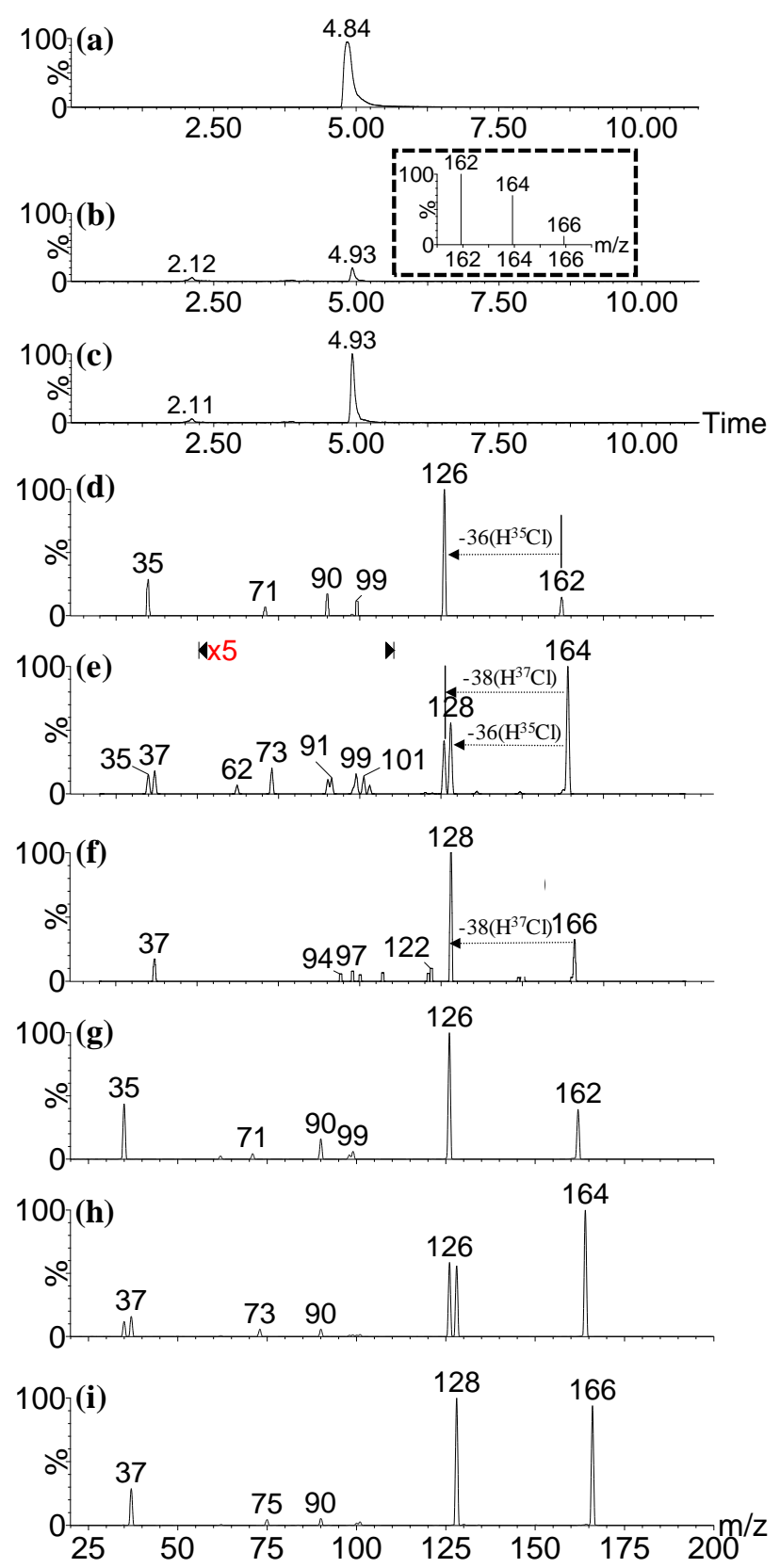

Figure S4. (a-c) UPLC/ESI-tqMS MRM $(162 \rightarrow 35,164 \rightarrow 35 / 37,166 \rightarrow 37)$ chromatograms of a 2,6dichloro-4-pyridinol standard, the simulated drinking water sample, and the water sample spiked with 2,6-dichloro-4-pyridinol, respectively; (d-i) UPLC/ESI-tqMS product ion scan spectra of $\mathrm{m} / \mathrm{z}$ $162 / 164 / 166$ of the water sample and the 2,6-dichloro-4-pyridinol standard, respectively. The $y-$ axes of charts (b) and (c) are on the same scale. 


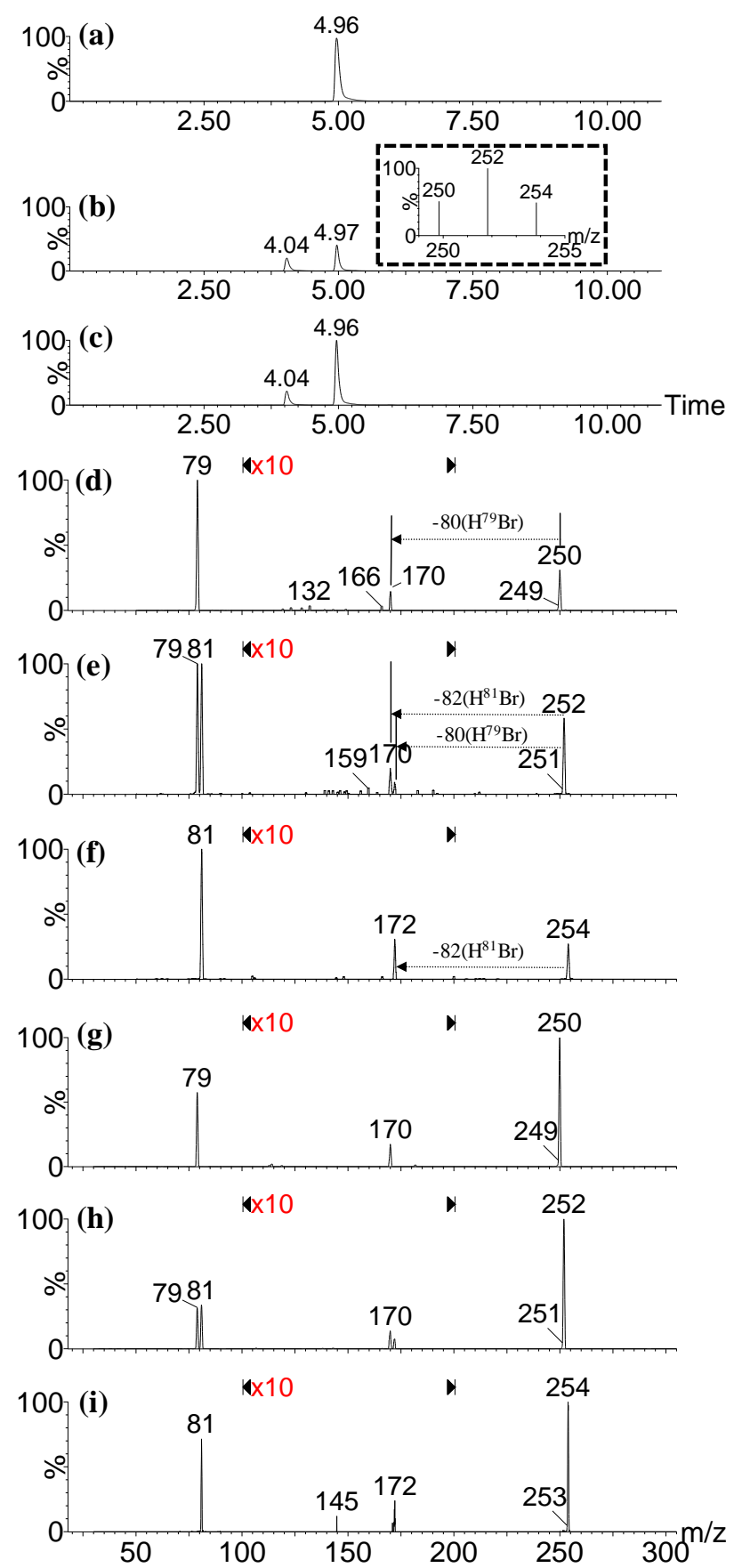

Figure S5. (a-c) UPLC/ESI-tqMS MRM $(250 \rightarrow 79,252 \rightarrow 79 / 81,254 \rightarrow 81)$ chromatograms of a 2,6dibromo-3-pyridinol standard, the simulated drinking water sample, and the water sample spiked with 2,6-dibromo-3-pyridinol, respectively; (d-i) UPLC/ESI-tqMS product ion scan spectra of $\mathrm{m} / \mathbf{z} 250 / 252 / 254$ of the water sample and the 2,6-dibromo-3-pyridinol standard, respectively. The $y$-axes of charts (b) and (c) are on the same scale. 


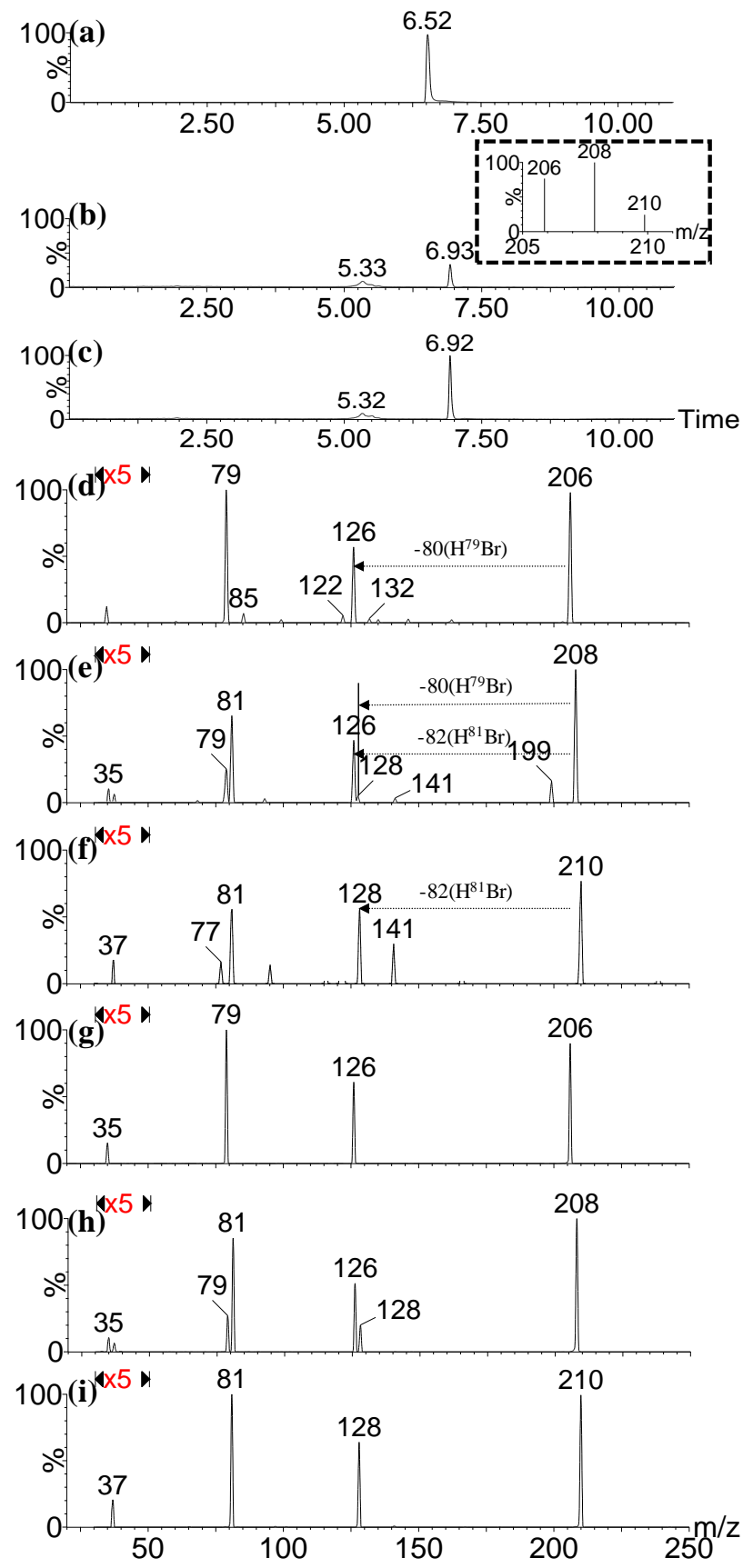

Figure S6. (a-c) UPLC/ESI-tqMS MRM $(206 \rightarrow 79,208 \rightarrow 79 / 81,210 \rightarrow 81)$ chromatograms of a 3bromo-2-chloro-5-pyridinol standard, the simulated drinking water sample, and the water sample spiked with 3-bromo-2-chloro-5-pyridinol, respectively; (d-i) UPLC/ESI-tqMS product ion scan spectra of $m / z, 206 / 208 / 210$ of the water sample and the 3-bromo-2-chloro-5-pyridinol standard, respectively. The y-axes of charts (b) and (c) are on the same scale. 

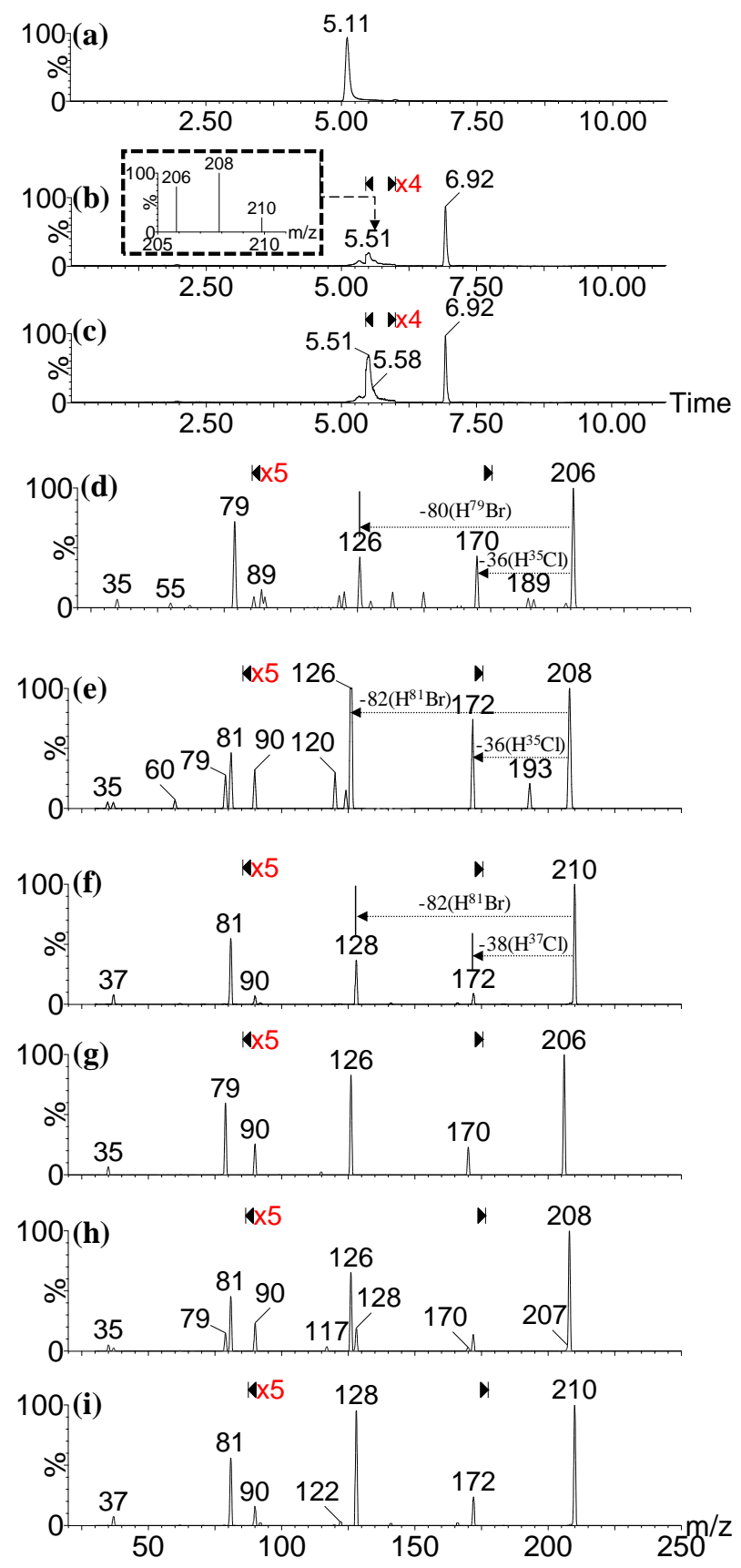

Figure S7. (a-c) UPLC/ESI-tqMS MRM $(206 \rightarrow 79,208 \rightarrow 79 / 81,210 \rightarrow 81)$ chromatograms of a 5bromo-2-chloro-3-pyridinol standard, the simulated drinking water sample, and the water sample spiked with 5-bromo-2-chloro-3-pyridinol, respectively; (d-i) UPLC/ESI-tqMS product ion scan spectra of $m / z$ 206/208/210 of the water sample and the 5-bromo-2-chloro-3-pyridinol standard, respectively. The $y$-axes of charts (b) and (c) are on the same scale. 


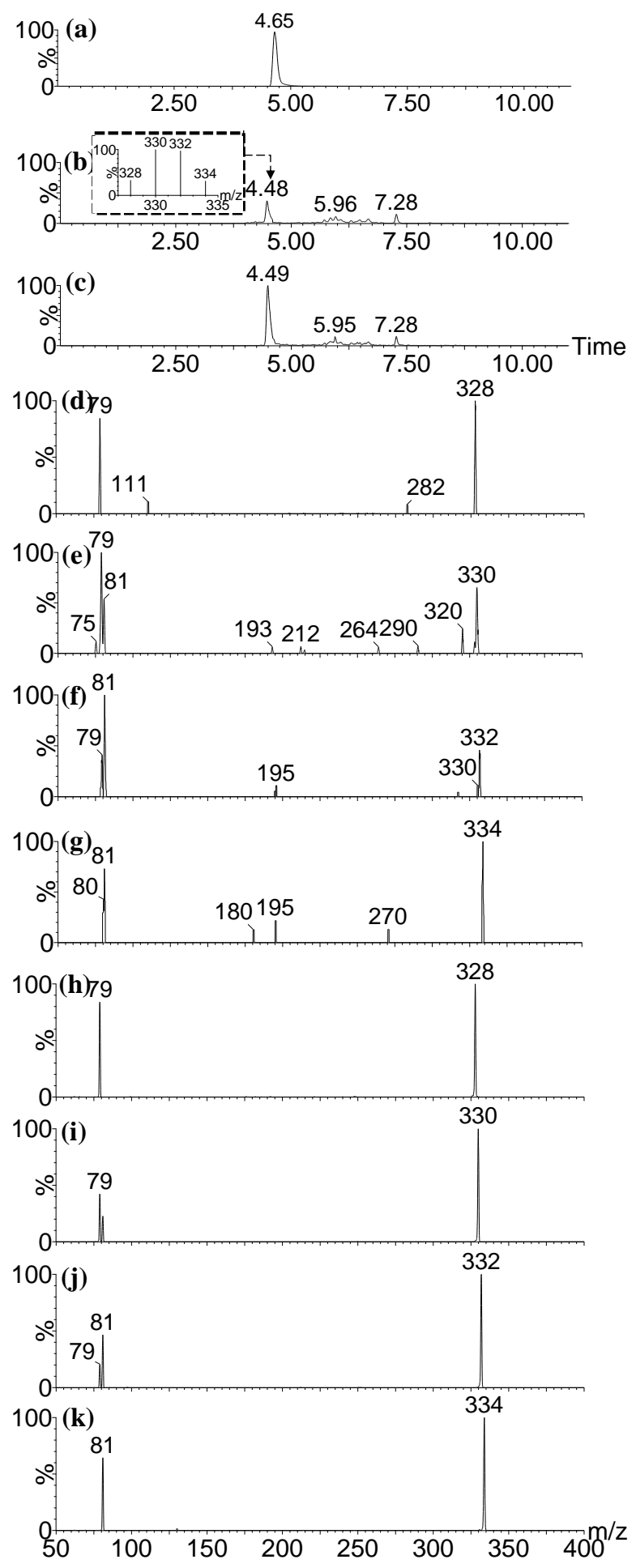

Figure S8. (a-c) UPLC/ESI-tqMS MRM $(328 \rightarrow 79, \quad 330 \rightarrow 79 / 81,332 \rightarrow 79 / 81,334 \rightarrow 81)$ chromatograms of a 2,4,6-tribromo-3-pyridinol standard, the simulated drinking water sample, and the water sample spiked with 2,4,6-tribromo-3-pyridinol, respectively; (d-k) UPLC/ESItqMS product ion scan spectra of $m / z 328 / 330 / 332 / 334$ of the water sample and the 2,4,6-tribromo3-pyridinol standard, respectively. The y-axes of charts (b) and (c) are on the same scale. 

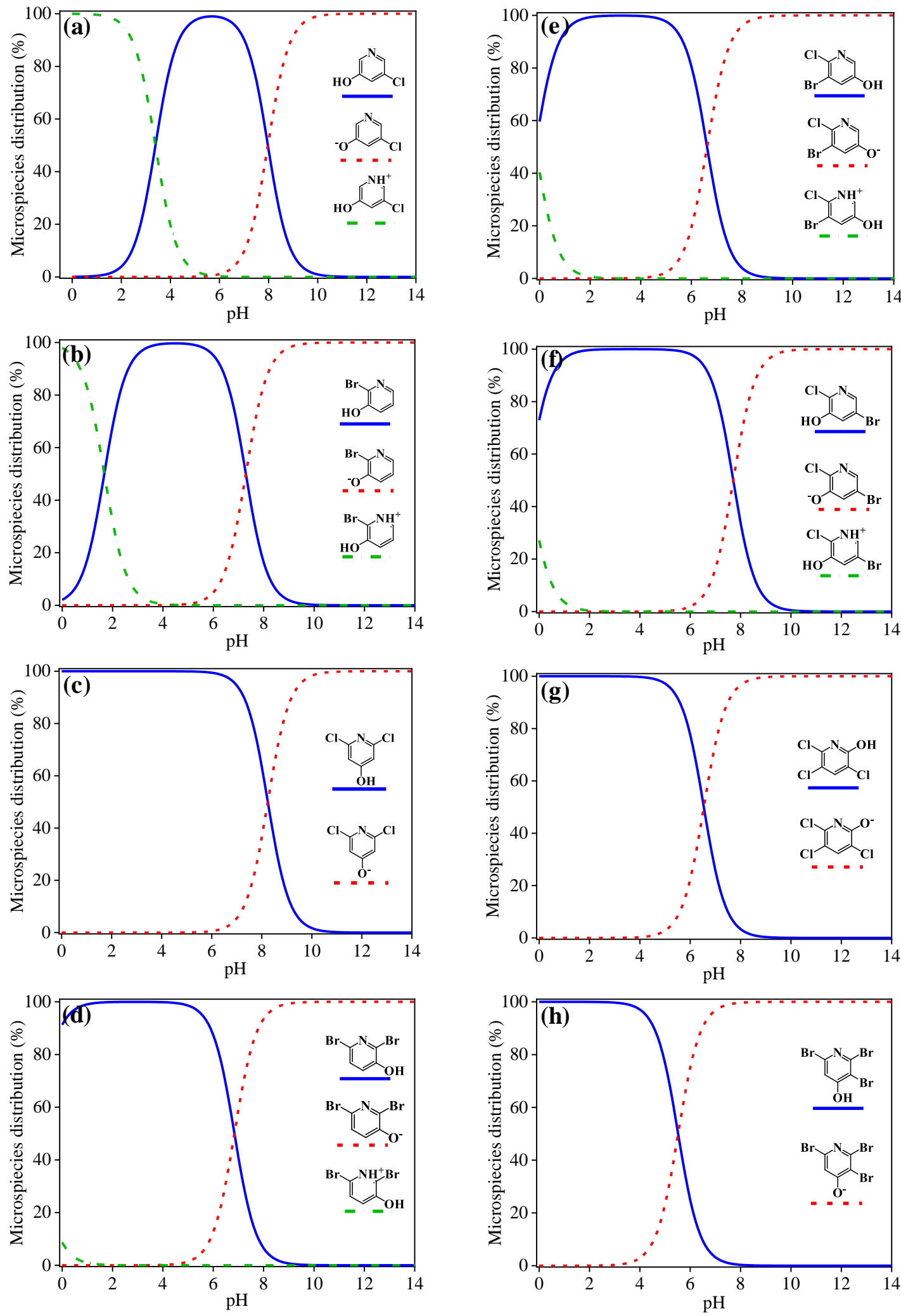

Figure S9. (a-h) The distribution patterns of the dissociated species of 5-chloro-3-pyridinol, 2bromo-3-pyridinol, 2,6-dichloro-4-pyridinol, 2,6-dibromo-3-pyridinol, 3-bromo-2-chloro-5pyridinol, 5-bromo-2-chloro-3-pyridinol, 3,5,6-trichloro-2-pyridinol, and 2,4,6-tribromo-3pyridinol with $\mathrm{pH}$, respectively. 

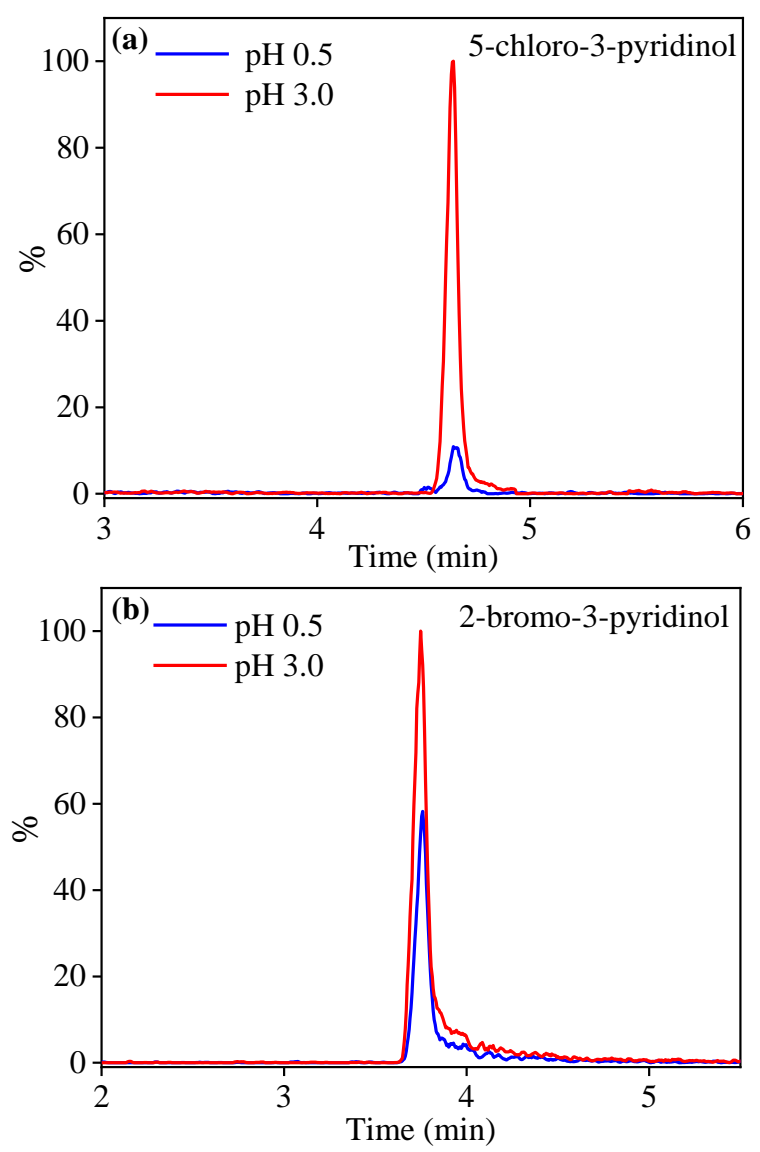

Figure S10. A comparison of peak areas in MRM chromatograms of (a) 5-chloro-3-pyridinol and (b) 2-bromo-3-pyridinol at extraction pH of 0.5 and 3.0. 

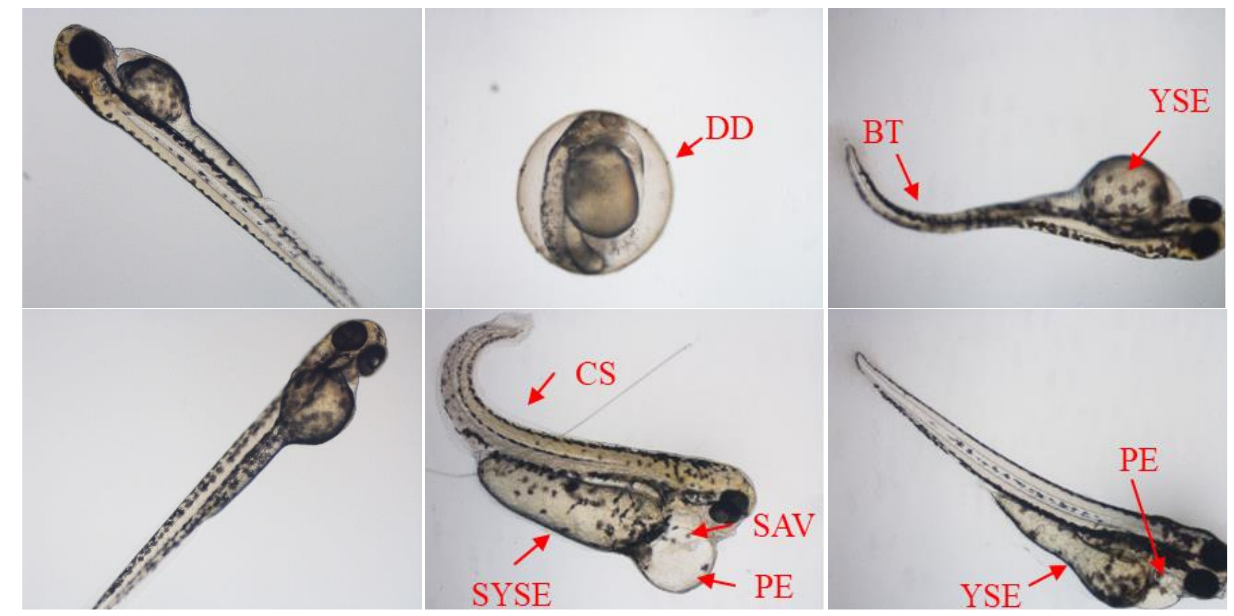

Figure S11. Morphological abnormalities of zebrafish embryos observed in the 2,4,6-tribromo-3pyridinol exposure at 72 hpf. SYSE: shortened yolk sac extension; BT: bent tail; CS: curved spine; PE: pericardial edema; YSE: yolk sac edema; DD: developmental delay; SAV: separation of the atrium-ventricle. 